\title{
Investigation Of The Improvement Building Envelope Impact On Energy Consumption Using Energy Audit
}

\author{
Fatiha Mokhtari ${ }^{1}$, Djaffar Semmar ${ }^{2}$, Mourad Chikhi ${ }^{1}$, Nachida Kasbadji Merzouk $^{1}$, Soumia Oukaci $^{2}$ \\ ${ }^{1}$ Unité de Développement des Equipements Solaires UDES/Centre de Développement des Energies Renouvelables CDER, BouIsmail \\ 42415, W. Tipaza, Algérie.
}

${ }^{2}$ Laboratoire Traitement De Surface Et Matériaux, Université Saad Dahleb-Blida 1, Route de Soumâa, BP 270, 09000 Blida-Algérie

\begin{abstract}
Effective evaluation on the thermal performance of building envelope plays an important role towards the reduction of energy consumption for space cooling and heating. In order to estimate the energy consumption for cooling, heating and the whole energy saving on the envelop designs; an improvements of thermal performances of this envelope are introduced. This trend is performed using a numerical study. The building is an office part of the Unit of Developmental for Solar Equipment (UDES) located at Bou-Ismail, an Algerian coastal city. Through the software PLEADES-COMFIE, building energy has been evaluated. The simulation results illustrate that; adding $90 \mathrm{~mm}$ thick insulation on the opaque walls and double glazing on windows produce a maximum saving of $50 \%$ and $10 \%$ annual energy required in heating and cooling. Also these proposed performances allow increasing indoor temperate of $4{ }^{\circ} \mathrm{C}$ in winter season and decreasing.
\end{abstract}

\section{Nomenclature}

\begin{tabular}{|l|l|l|}
\hline Quantity & Symbol & SI Unit \\
\hline $\begin{array}{l}\text { American Society } \\
\text { of Heating, } \\
\text { Refrigerating and } \\
\text { Air-conditioning } \\
\text { Engineers }\end{array}$ & ASHARAE & \\
\hline Thickness & $\mathrm{e}$ & $\mathrm{cm}$ \\
\hline Double Glazing & $\mathrm{DG}$ & \\
\hline $\begin{array}{l}\text { Energy } \\
\text { Conservation } \\
\text { Opportunities }\end{array}$ & $\mathrm{ECOs:}$ & \\
\hline $\begin{array}{l}\text { Office } \\
\text { Total resistance } \\
\text { of the wall }\end{array}$ & $\mathrm{RT}$ & $\mathrm{m}{ }^{2} \mathrm{~K} / \mathrm{W}$ \\
\hline $\begin{array}{l}\text { Overall heat } \\
\text { transfer } \\
\text { coefficient }\end{array}$ & $\mathrm{U}-\mathrm{Value}$ & $\mathrm{W} / \mathrm{m}^{2} \mathrm{~K}$ \\
\hline
\end{tabular}

\section{Introduction}

The Algerian national program for energy efficiency and renewable energy sets a reduction target of $40 \%$ of

\footnotetext{
* Corresponding author: mokhtari.fatiha@gmail.com
}

energy consumption of the existing buildings on the horizon 2030 [1]. This goal requires major actions throughout of the real estate (residential and tertiary sector). The priority actions relate in particular to the development of energy efficiency in the buildings for reducing energy use for space cooling and heating. In order to achieve this, adequate audit is required before including passive and active systems. According to the statistics, office building is one of the largest energy intensive typology, adding retail building that account for over $50 \%$ of the total energy use among Many research works have focused on studying the effect of climate on annual energy consumption with the integration of different passive retrofitting scenarios in office buildings [3, 4]. Alajmi [5] developed a study on Energy audit of an educational building. For this investigation, the author applied the ASHREA guidelines. This process allows identify any energy conservation opportunities (ECOs) classified as nonretrofitting (no or minimal cost) and retrofitting (with cost) recommendations. The results showed that the retrofitting ECOs can save up to $49.3 \%$; this results in a $52 \%$ total saving. Rhodes [6] presents a method analysis of a unique dataset of 4971 energy audits performed on homes in Austin, Texas in 2009-2010. Their work aims to quantify the prevalence of typical air-conditioner design and installation issues such as low efficiency, oversizing, duct leakage, and low measured capacity, and estimate the impacts that resolving these issues would have on peak power demand and cooling energy consumption. The methods described herein could allow electric utilities in similar climates to make better- 
informed decisions when considering efficiency improvement programs. In the study of Botsaris [7], a new method for the certification of the energy behavior in building is realized. The proposed method tends to simulate the building heat losses and the heat flow. This study presents an analysis of energy audits applied on office building, which is part of the Development Unit for Solar Equipment (UDES) located at Bou-Ismail, an Algerian coastal city. The numerical study is developed using PLEADES-COMFIE Software. The investigation consists to quantify the winter and summer energy consumption before and after the proposed improvements on the building envelope.

\section{Prototypical Office Building Design}

The project consisted in office building with approximately $125,32 \mathrm{~m} 2$ located in the municipality of Bou-Ismail (coastal city of the metropolitan city of Tipaza) whose geographic coordinates are respectively (latitude: $36^{\circ} 38^{\prime}$, longitude: $2^{\circ} 41^{\prime}$, Altitude: $15 \mathrm{~m}$ ). The site is characterised by an average exterior temperature respectively $6^{\circ} \mathrm{C}$ in winter and $31^{\circ} \mathrm{C}$ in summer. The office building is on a single floor and consists of seven offices and a library (figure.1). The total area for the windows is less on the south side than on the west side. The occupancy is regular from 8 am to 4 pm, 5 days per week during the year. The properties of the various materials used in this building are summarized in Table 1.

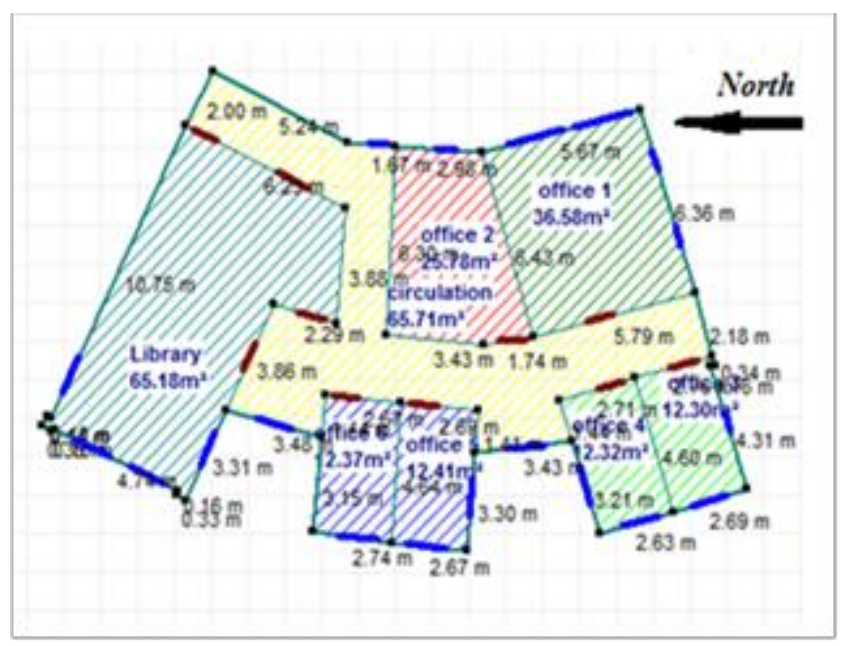

Fig 1. Floor plan of the prototype building showing the details of the offices

\begin{tabular}{|l|l|c|c|c|}
\hline & Composition & $\begin{array}{c}\mathrm{e} \\
(\mathrm{cm})\end{array}$ & $\begin{array}{c}\lambda \\
(\mathrm{W} / \mathrm{m} \mathrm{K})\end{array}$ & $\begin{array}{c}\mathrm{R}_{\mathrm{T}} \\
\left(\mathrm{m}^{2} \mathrm{~K} / \mathrm{W}\right)\end{array}$ \\
\hline \multirow{5}{*}{$\begin{array}{l}\text { External } \\
\text { wall }\end{array}$} & Plaster & 2 & 0.35 & \\
& ClayBrick & 10 & 0.5 & \\
& Air Gap & 10 & 0.025 & 0.78 \\
& Clay Brick & 10 & 0.5 & \\
& Cement coating & 2 & 0.35 & \\
\hline \multirow{5}{*}{ Floor } & False ceiling & 1 & 0.35 & \\
& Air Gap & 10 & 0.025 & \\
& Mortar & 25 & & 0.71 \\
& Concrete & 3 & 1.75 & \\
& Mortar + sand & 5 & & \\
& tiling & & & \\
& False ceiling & 1 & 0.35 & \\
& Air Gap & 10 & 0.025 & \\
& Mortar & 25 & - & 0.61 \\
& Concrete & 5 & 1.75 & \\
& Bitumen & 2 & 0.23 & \\
& Mortar + sand & 5 & - & \\
& tiling & & & \\
\hline
\end{tabular}

The overall heat transfer coefficient $\mathrm{U}$-value of the three elements of the building envelope are respectively: 1.25 $\mathrm{W} / \mathrm{m}^{2} \mathrm{~K}$ for the external wall, $1.62 \mathrm{~W} / \mathrm{m}^{2} \mathrm{~K}$ for the ceiling and $0.70 \mathrm{~W} / \mathrm{m}^{2} \mathrm{~K}$ for the floor. The windows of the building are single glazed with a overall heat transfer coefficient U-value of $4.4 \mathrm{~W} / \mathrm{m}^{2} \mathrm{~K}$ [8].

\section{Energy Simulation Of An Office Building}

The study is numerical and executed using the software PLEADES-COMFIE calculates thermal loads of buildings by the heat balance method. COMFIE performs hourly simulations of buildings, in order to provide mechanical, energy and architectural engineers or architects with accurate estimates of a building's energy needs and temperature profiles [9]. The zone models of COMFIE are based upon a finite volume method on which a modal reduction technique is applied.

Among the simulation scenarios considered are:

1. Weather data used is a 'meteonorm' file of Tipaza city

2. A set point indoor temperature of $21^{\circ} \mathrm{C}$ and $27^{\circ} \mathrm{C}$ respectively in winter and in summer is taken inside the office

3.The simulation is running in winter (from 07 to 14 January) and summer (from 16 to 23 July) during the most unfavorable week respectively.

4. The occupation scenario is as follows: each office is occupied by 2 researchers, except the library, there are 3 employees and 12 regular students.

5.The duration of the occupancy is: $08 \mathrm{~h}-12 \mathrm{~h}$ and $13 \mathrm{~h}-$ $17 \mathrm{~h}$.

6. For both winter and summer, the ventilation air flow is $0,6 \mathrm{~V} / \mathrm{h}$ 
In this study, we take into account three steps cases studies:

- Step 1: Energy needs calculated without improvements.

- Step 2: An intermediate insulation of $9 \mathrm{~cm}$ expanded polystyrene (EPS) on external walls and roof [8].

- Step 3: Double- glazed windows with an overall U-value of $1.2 \mathrm{~W} / \mathrm{m} 2 \mathrm{~K}$.

After adding a $9 \mathrm{~cm}$ thick expanded polystyrene layer (EPS) on the opaque walls (external walls, roof and floor), it is noted a major falls in the overall heat transfer coefficient U-value for opaque walls. Respectively; external walls $U$ - value is $0.34 \mathrm{~W} / \mathrm{m} 2 \mathrm{~K}$, roof $\mathrm{U}$ - value is $0.35 \mathrm{~W} / \mathrm{m} 2 \mathrm{~K}$ and floor $\mathrm{U}-$ value is $0.36 \mathrm{~W} / \mathrm{m} 2 \mathrm{~K}$. This results lead to a reduction in thermal losses from walls and provides substantial savings in the seasons energy requirements winter and summer). This improvement in overall heat transfer coefficient can also have a considerable effect on the value of the indoor temperature. This ensures a higher indoor temperature, more stable and with few fluctuations in comparison with the outdoor temperature.

\section{Results and Discussions}

\subsection{Total Energy Needs assessment of Heating in office building}

Among parameters affecting the energy needs in buildings are building orientation, building area and the materials composition of external walls. In this research, we study the impact of these parameters on the building energy needs.

Figure 2 presents the winter energy needs of the studied office building. According to the figure 2, it can be seen that the most important energy needs are recorded by offices $\mathrm{O} 2, \mathrm{O} 3 / 4$, and $\mathrm{O} 5 / 6$. This trend may be the results of the important internal wall surface $(46.09 \mathrm{~m})$ in contact with the hall, which favors thermal losses and possibly increases the energy needs $(90 \mathrm{KWH} / \mathrm{m}$ ).

For the offices $3 / 4,5 / 6$, external walls present the more great area (see Figure 1) which leads to significant surface transmission losses. The offices $\mathrm{O} 4$ and $\mathrm{O} 6$ that are adjacent offices to the offices $\mathrm{O} 3$.and $\mathrm{O} 5$ respectively, have a north orientation, which has a disadvantage for the heating mode. The energy needs of the library are lower than those of other offices, considered its orientation, reduced external surface walls and the factor of occupation which plays a very important role. Step2, represents the addition of insulation to the opaque walls. It can be noted a significant reduction in energy requirements for all offices. The reduction is almost $50 \%$ for all offices. The addition of the DG (step3) reduces the energy requirements of the studied offices by half. These results show that the opaque wall insulation and double-glazing have an important effect on the energy building requirements.

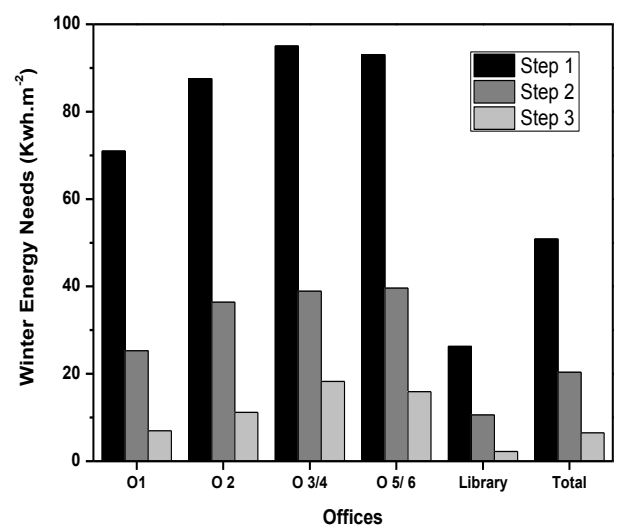

Fig 2. Winter energy needs in office building before and after improvements

\subsection{Total Energy Needs assessment of Heating in office building}

Since the building is located in a coastal region (humid climate), the energy requirements for cooling are not important and can be controlled only by improving the performance of the building envelope. The results illustrated on figure 3 show the energy needs for cooling before and after Improvements. For the summer season, with the proposed improvements in the performance of the building envelope (step 2 and step 3), it is noted a net reduction of $10 \%$ on the energy needs in cooling.

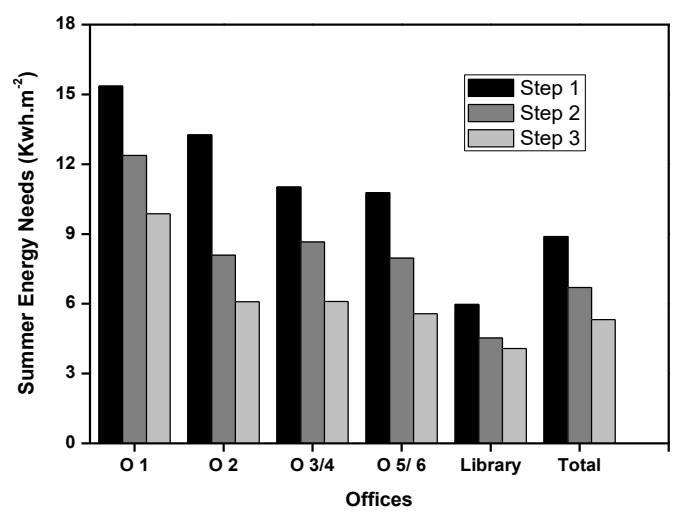

Fig 3 . Energy needs for cooling in office building before and after improvements

\subsection{Indoor Temperature results}

\subsubsection{Winter season}

The figures $4 \mathrm{a}, 4 \mathrm{~b}, 4 \mathrm{c}$ represent the indoor temperature respectively before improvement, with insulation and double glazing adds to the insulation during the worst week in winter. From the figure $4 a$, it is noted the following results: 
- All indoor Temperatures in offices do not exceed $16^{\circ} \mathrm{C}$.

- Indoor temperatures have lower fluctuations than outdoor temperatures probably due to the inertia of exterior walls.

- The highest indoor temperature is recorded in the Library; which can be explained by the effect of occupations (15 occupants).

After adding insulation, the indoor temperatures obtained are slightly higher (figure $4 \mathrm{~b}$ ); these reach the value of $19^{\circ} \mathrm{C}$ (an increase of $3^{\circ} \mathrm{C}$ to $4^{\circ} \mathrm{C}$ ). The $\mathrm{O} 1$ records the highest temperature compared to the temperatures obtained in the other offices; this is due to the fact that the $\mathrm{O} 1$ has the important area of external wall $(25.29 \mathrm{~m})$ facing South. The figure $4 \mathrm{c}$ representing the addition of the DG gives temperatures close to the internal temperatures obtained from the addition of the insulation (Figure 4b), which allows to conclude that the DG doesn't have a great effect on the indoor temperatures since the percentage of windows in all offices represents $1 / 5$ of the total area of external walls.

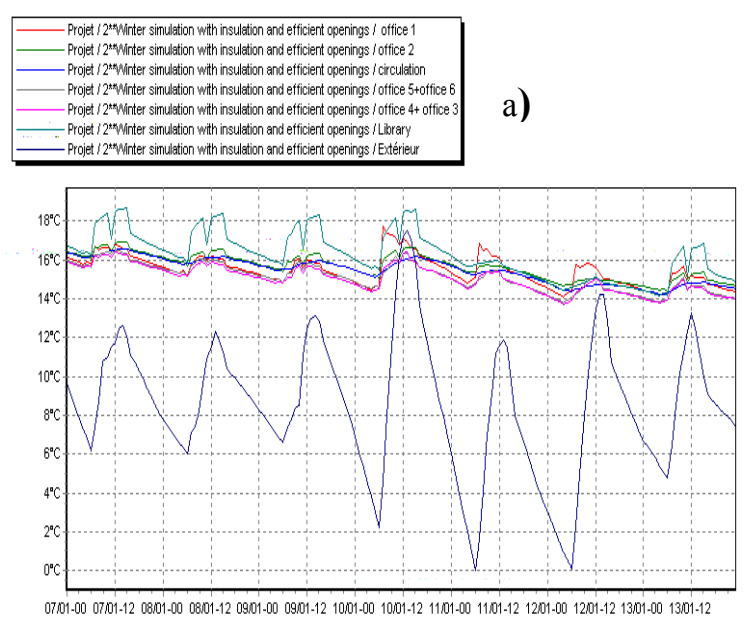

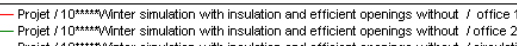

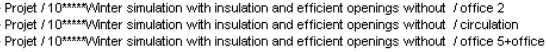

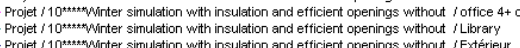

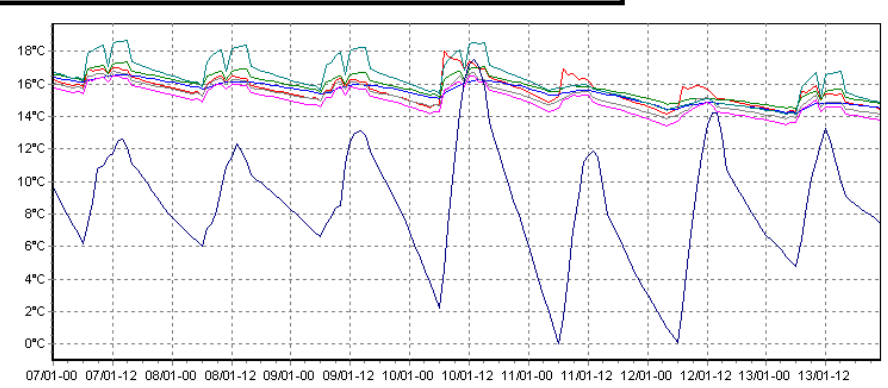

\section{b)}

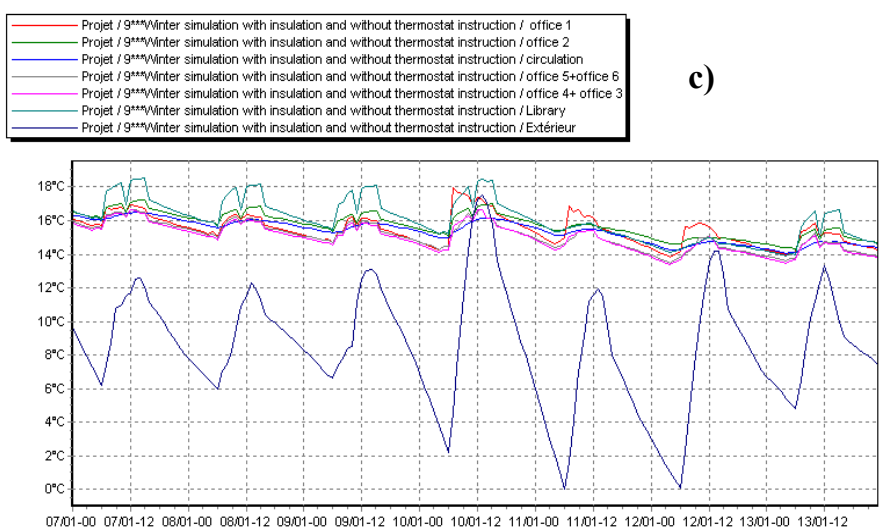

Fig 4.Indoor temperatures; a) before improvement; b) with insulation only; c) with insulation + DG.

\subsubsection{Summer season}

The figures $5 \mathrm{a}, 5 \mathrm{~b}, 5 \mathrm{c}$ represent the indoor temperature respectively before improvement, with insulation and double glazing adds to the insulation during the worst week in summer. From the figure $5 \mathrm{a}$, it is noted the following:

- The indoor temperatures recorded in the offices reach the values of $\mathrm{T}=35^{\circ} \mathrm{C}$ during the worst week in summer.

- $\mathrm{T}$ between indoor and outdoor temperatures reaches 8

${ }^{\circ} \mathrm{C}$ to $9{ }^{\circ} \mathrm{C}$.

- Office 1 records the highest temperature, this is due to the solar gain. The second temperature recorded is that of the library (under the effect of occupation).

After improvement of the envelope (Step 2), a decrease of $2{ }^{\circ} \mathrm{C}$ to $3{ }^{\circ} \mathrm{C}$ is noted. The temperatures recorded after the addition of the double glazing (Figure 5c) are close to those obtained from the addition of the insulation of the opaque walls (Figure 5b), sometimes they have higher values. This can be interpreted as the fact that; in summer the DG is a disadvantage as it can lead to greenhouse effect inside offices and causes a discomfort for the occupants. In summer season, the simulation results indicate that adding the insulation (step 2) leads to a discomfort rate of $73.33 \%$. Incorporating a DG (Step 3) causes a discomfort rate of $81.62 \%$. 

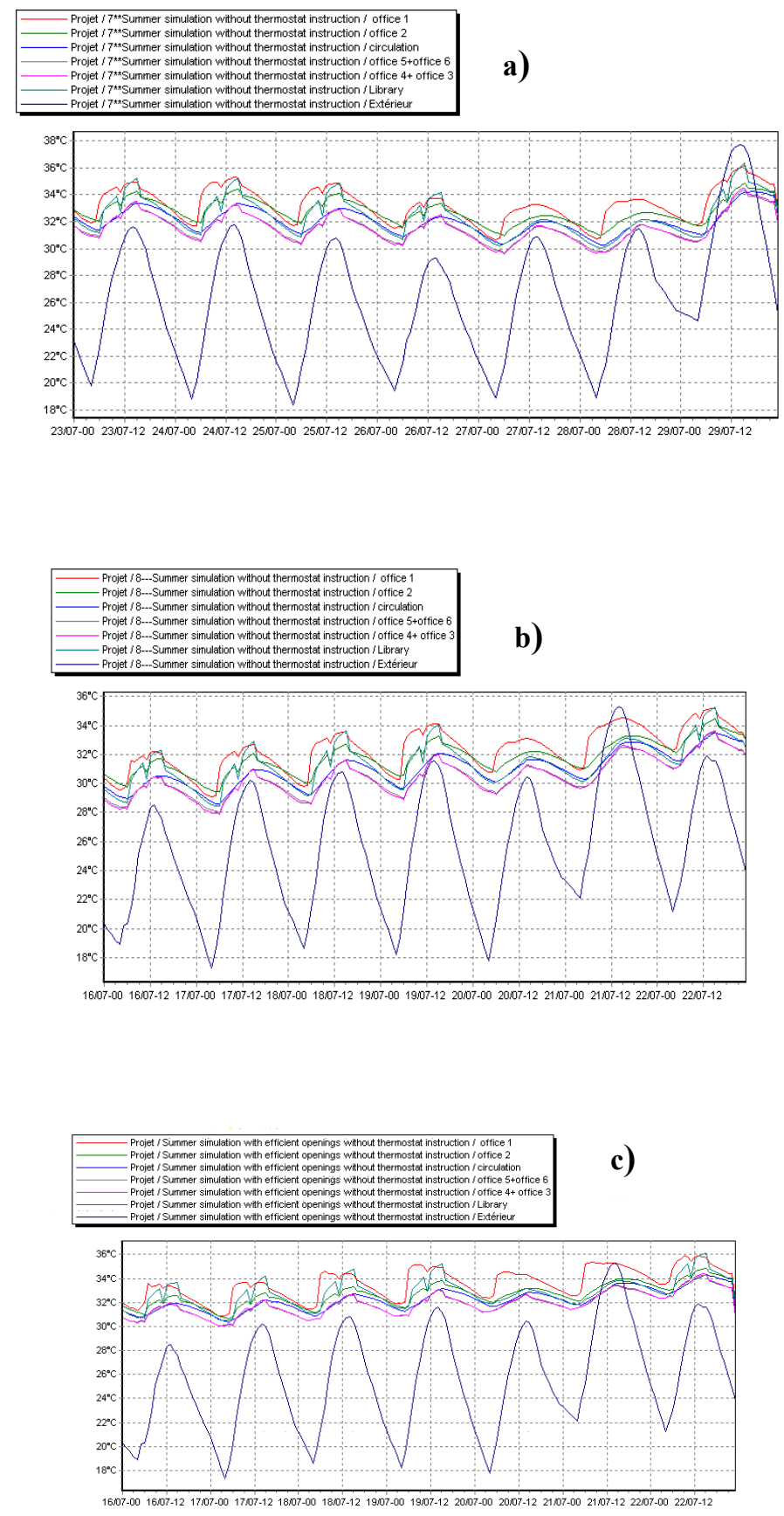

Fig 5. Indoor temperatures; a) before improvement; b) with insulation only; c) with insulation $+\mathrm{DG}$.

\section{Conclusion}

This study is conducted as a means to examine some energy conservation opportunities on annual cooling and heating in office buildings. The case study is an office building part of the Developmental Unit for Solar Equipment (UDES) located at Bou-Ismail, an Algerian coastal city. Through the software PLEADES-COMFIE, building energy has been evaluated. The effect of the parameters like the climatic conditions (location), insulation and adding DG, building area, building orientation and occupation on annual building energy requirement is examined and the results of indoor temperatures obtained are presented for winter and summer seasons.

-.An introduction of $90 \mathrm{~mm}$ thick insulation produces the maximum saving of $50 \%$ annual requirement heating energy and about $10 \%$ annual requirement cooling energy in all studied offices.

-.The simulation results illustrate the effect of adding DG on building energy requirement. The effect is significant in offices with important window areas (O1, $\mathrm{O} 2$, Library). Total heating energy requirement decrease for $10 \%$.

-.For the summer season, since the office building is located on the littoral (moderate climate), the effect of insulation on external walls and double glazing on cooling energy requirement isn't very important, it is possible to obtain $10 \%$ energy saving.

-.Since the occupants spend their time indoors, there should be serious concerns about the indoor temperature and the necessary thermal comfort. The simulation results show that, in winter season, the improvement building envelope (insulation $+D G$ ) can increase the indoor temperature to reach the temperature range of thermal comfort. However, in summer, the simulation results of indoor temperature show that when the step 2 is applied, it can be decreased temperature inside offices by $2^{\circ} \mathrm{C}$ to $3^{\circ} \mathrm{C}$. The double glazing can be a disadvantage as it can create greenhouse effect inside offices and causes a discomfort for the occupants.

Furthermore, we conclude that efficiency improvements alone (insulation + DG) could possibly reduce annual energy demand about $50 \%$ in winter which will achieve the action plan implemented by the government. It can be noticed that the impact of the opaque walls insulation is more important than the double glazing on windows regarding the windows area which represents $1 / 5$ of the total area of external walls. Reducing the energy consumption of the office building is an opportunity to plan to integrate a solar installation for heating which remains a useful axis in the application of building energy efficiency. 


\section{References}

1. MEM, Ministry of Energy and Mines, http://www.energy.gov.dz/francais/index.php? (2014)

2. L.Pérez-Lombard, J.Ortiz, C .Pout, Energy Build, 40 (3) ( 2008)

3. E. Dascalaki, M. Santamouris, Build and Env 37, pp 557-567( 2002)

4. N. Eskin, H.Türkmen, Energ and Build 40, pp 763-773( 2008)

5. A.Alajmi , Energ and Build 47 , pp 122-130( 2012)

6. J.D. Rhodesa, B.Stephens, M.E.Webbe, Energ and Build 43, pp 3271-3278(2011)

7. Botsarisa, N.Pantelis; S.Prebezanos, , Build and Env 39 , pp 195 - 199(2004)

8. DTR C3-2, Thermal regulation of residential buildings e calculating methods for determining building heat losses. Algiers: CNERIB; [in French](1997)

9. T. Salomon, R. Mikolasek and B.Peuportier, Theme day SFT-IBPSA (2005) 